\title{
Scolex development, morphology and mode of attachment of Wenyonia virilis Woodland, 1923 (Cestoidea, Caryophyllidea)
}

\author{
Mohammed H. Ibraheem ${ }^{*}$ and John S. Mackiewicz ${ }^{2}$ \\ ${ }^{1}$ Department of Zoology, Faculty of Science, Minia University, El-Minia 61519, Egypt; ${ }^{2}$ Department of Biological Sciences, \\ State University of New York, Albany, NY 12222, U.S.A.
}

\begin{abstract}
Development and morphology of the scolex and mode of attachment of Wenyonia virilis Woodland, 1923, a caryophyllaeid cestode from the silurid Nile fish Synodontis schall (Bloch et Schneider, 1801), were studied by means of light and scanning electron microscopy (SEM). Scolex and genital primordia changes through four stages of juvenile development are described. Longitudinal ridges do not appear on the scolex until the cestode has well defined genital primordia. This is in stark contrast to other caryophyllidean genera in which the basic morphology of the adult scolex becomes evident at the procercoid stage in the oligochaete intermediate host. The scolex of the adult has 13 to 19 prominent longitudinal ridges and deep furrows that come together at the apex to form an apical ring, a protrusible terminal introvert within the apical ring that forms a deep apical pouch when fully retracted, and a central group of Faserzellen. The scolex of $W$. virilis appears similar to the rugomonobothriate scolex of another African caryophyllid, Monobothrioides chalmersius (Woodland, 1924). Comparisons are made with other caryophyllideans having a scolex with a terminal structure: Monobothrium Diesing, 1863, Djombangia Bovien, 1926 and Caryoaustralus Mackiewicz et Blair, 1980. The terminal introvert may be responsible for attachment in early juvenile stages, but may be supplemented by the longitudinal ridges and furrows later in development. Host tissue appears to be drawn into these furrows that function as weak organs of attachment. We could not determine how the introvert of adult worms functions in attachment. At the site of attachment, the mucosa showed necrosis and degeneration and the submucosa exhibited vacuolization and infiltration with lymphocytes and leucocytes.
\end{abstract}

\section{Key words}

Caryophyllidea, Wenyonia virilis, scolex attachment, scolex morphology, terminal introvert, SEM

\section{Introduction}

Tapeworms of the order Caryophyllidea have been reported from freshwater siluriform and cypriniform fishes in Africa, Asia, Australia, Europe, and North America (Mackiewicz 1994). They are characterized by having a monopleroid body form and a life cycle involving tubificid worms (Annelida, Oligochaeta) as intermediate hosts. The genus Wenyonia Woodland, 1923 is known only from Africa. Of the eight species reported from Africa (Khalil and Polling 1997), three are known from the Nile: W. acuminata Woodland, 1923; W. minuta Woodland, 1923 and W. virilis Woodland, 1923.

First described by Woodland (1923) from the Nile River siluroid fish Synodontis schall (Bloch et Schneider, 1801) in Sudan, W. virilis has been widely reported from Egypt (Khalil and Polling 1997). Most reports concern surveys (Fahmy et al. 1976, El-Naffar et al. 1983), brief descriptions (Imam et al.
1991), pathology (Banhawy et al. 1975, 1979), or some observations on surface tegumental structures (Garo et al. 2000). The present study focuses on the development of the scolex of $W$. virilis, with special attention to the nature of the terminal introvert and morphology of the scolex of adult worms as revealed by the scanning electron microscope.

\section{Materials and methods}

Cestodes were recovered from the catfish Synodontis schall (Siluriformes, Mochokidae) collected by fisherman in the Nile River at El-Minia, Upper Egypt. In most cases, live fish were taken to the laboratory and examined immediately. Worms were removed from the intestine and placed in a $0.75 \%$ saline solution to observe scolex movements under low magnification of a dissecting microscope. Specimens for whole 
mounts were fixed in hot formalin-acetic acid solution $\left(60^{\circ} \mathrm{C}\right)$ and stained in acid-alum-carmine. Some detached adult worms and others attached to pieces of the intestinal mucosa were fixed in Bouin's fluid, embedded in paraffin, stained with haematoxylin and eosin, Mallory's triple, or toluidine blue stain and serially sectioned at $5 \mu \mathrm{m}$ thickness.

Specimens for scanning electron microscopy were immediately fixed in a solution of $2.5 \%$ glutaraldehyde buffered in $0.1 \mathrm{M}$ sodium cacodylate ( $\mathrm{pH} 7.4$ ) at $4^{\circ} \mathrm{C}$ for $24 \mathrm{hrs}$. Post-fixation treatment was carried out in $2 \%$ osmium tetroxide in the same buffer for $2 \mathrm{hrs}$ at $4^{\circ} \mathrm{C}$. After washing several times in buffer, specimens were dehydrated in a graded acetone series, transferred to liquid $\mathrm{CO}_{2}$ and critical point dried. Specimens were sputter-coated with approximately $20 \mathrm{~nm}$ gold/palladium (using JEOL JFC-1100 E ion sputtering device), and examined with a stereoscan JEOL JSM-5400 LV at $15 \mathrm{kV}$.

Measurements are presented as means followed by ranges in parentheses and were taken on relaxed, unflattened, fixed specimens. Drawings were made with the aid of a camera lucida.

The term "procercoid", as commonly used throughout the helminthological literature, is used instead of "plerocercoid" as recently proposed by Chervy (2002) for the same stage.

\section{Results}

\section{Juvenile}

A total of 427 juveniles was collected from 31 of 70 infected fish (44\%). The immature cestodes were categorised into four developmental stages, based on the state of maturation of genital primordia. At stage 1 (up to $3 \mathrm{~mm}, \mathrm{n}=185$ ), genital primordia appear as a dark longitudinal streak, enlarged at both ends, occupying the middle third of the body (Fig. 1A). The scolex is large and constitutes approximately one-fourth of the total body length. It is globular in shape, smooth, devoid of longitudinal ridges and characteristically has a terminal introvert at the apex. Despite its globular shape, the scolex is quite mobile. It first elongates its anterior extremity bearing the introvert, then retracts and returns to the globular form again. This process was repeated multiple times during which the introvert was repeatedly extended and withdrawn back into the scolex apex. Juveniles at this stage were found embedded in the mucus layer covering the intestinal mucosa.

In stage $2(3-5 \mathrm{~mm}, \mathrm{n}=132)$, the longitudinal streak elongates and shows differentiation into a slightly coiled primordial uterine tube with an anterior cap of testes primordia (Fig. 1B). The scolex is globose, still smooth and without any longitudinal ridges. The terminal introvert is somewhat larger.

In stage $3(5-7.5 \mathrm{~mm}, \mathrm{n}=98)$, especially young individuals (approximately $5-6.5 \mathrm{~mm}$ ), have the primordial uterine tube more coiled and a small female genital pore appears at its anterior extremity. The testes become more prominent and appear as a primordial cap. At this stage, the scolex begins to assume its distinctive morphology as longitudinal ridges ap- pear on the lower half of the scolex. There are 10-12 ridges and they are distributed evenly around the globular scolex (Fig. 1C). A smooth circular area on the apex of the scolex surrounds the apical ring. In larger and presumably older individuals of stage 3 (approximately $6.5-7.5 \mathrm{~mm}$ ), the primordial uterine tube develops further and assumes a twisted zigzagshape (Fig. 1D). Differentiation of vitelline follicles takes place on both sides of testes and uterus, but these organs are not distinguishable from each other except by position. Ridges are more fully developed and extend along the entire length of the scolex that now assumes the basic morphology found in the adult.

In stage $4(7.5-11 \mathrm{~mm}, \mathrm{n}=39)$, there is further differentiation of the sexual primordia and scolex. The follicular nature of the ovary becomes better defined. In smaller individuals $(7.5-9 \mathrm{~mm})$ the zigzag-shaped uterine tube is transformed into a small, loosely coiled uterus. Testes and vitellaria are beginning to differentiate from each other (Fig. 1E). The number of ridges on the scolex is increased (10-17). The terminal introvert is more prominent and the circular smooth area surrounding the apical ring is obviously smaller than in stage 3. In larger individuals (approximately $9-11 \mathrm{~mm}$ ) uterine folds are wider and more numerous. Vitellarian and testicular fields are fully differentiated. The scolex at this stage has well-developed longitudinal ridges, or rugae, and terminal introvert. A male genital pore appears anterior to the female genital pore. The external body form of this stage (Fig. 1F) resembles the adult stage but differs in lacking well-developed postovarian vitelline follicles. At higher magnification, excretory ducts and bladder are apparent.

\section{Adult}

The body of 20 gravid adults (Fig. 1G) is elongated, dorsoventrally flattened and measures $14.7(8-20) \mathrm{mm}$ long by 1.6 (0.9-1.9) mm wide. The large scolex is conical, and may be round to flattened in cross-section (Figs 2 and 8, respectively). It measures 1.5 (1.0-2.4) $\mathrm{mm}$ long by 2.4 (1.6-3.6) $\mathrm{mm}$ wide, and is approximately $10 \%$ of the total worm length. There are 16 (13-19) conspicuous longitudinal ridges alternating with a similar number of longitudinal furrows (Figs 4, 7 and 8). A highly folded tegumental surface covers the longitudinal ridges (Figs 4 and 7). From observations of live specimens in physiological saline, the scolex is highly mobile with stretching and contracting movements that involve the introvert. The introvert was best observed in large individuals in which it reaches its maximum development (Figs 6 and 8). In whole mounted specimens, the typically rugose or ridged scolex exhibits an apical introvert in various states of contraction (Figs 2-8). When extended, the scolex apex may be bluntly rounded (Fig. 2) or flattened in profile (Figs 7 and 8) when the introvert is retracted. When fully extended (Figs 2 and 3 ) the very apex is rather smooth with little trace of the apical ring, so evident when the introvert is fully retracted (Fig. 6). A partially everted introvert forms a crease that separates it from the apical ring (Figs 4 and 5). As the central portion of the intro- 

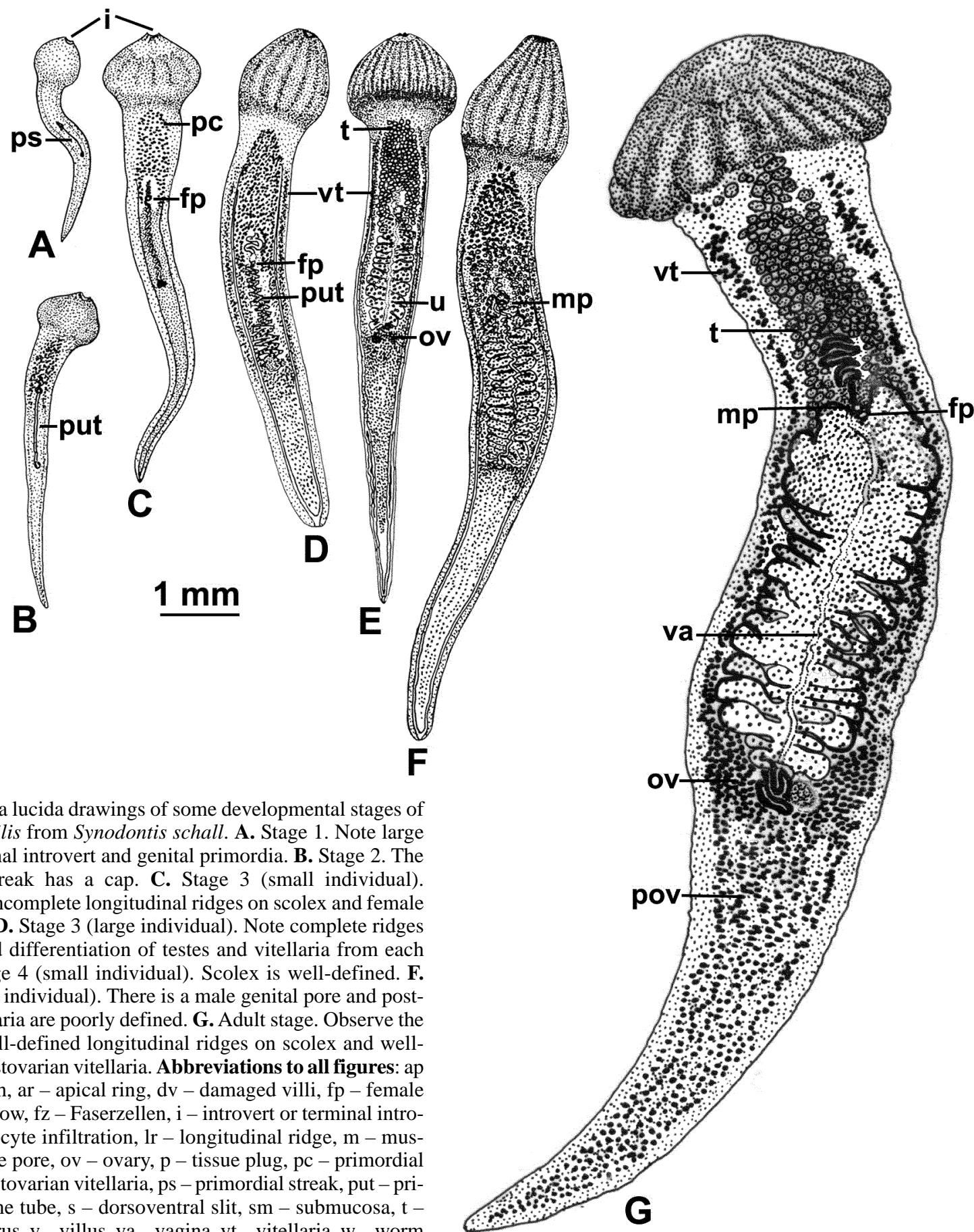

Fig. 1. Camera lucida drawings of some developmental stages of Wenyonia virilis from Synodontis schall. A. Stage 1. Note large scolex, terminal introvert and genital primordia. B. Stage 2. The primordial streak has a cap. C. Stage 3 (small individual). Observe the incomplete longitudinal ridges on scolex and female genital pore. D. Stage 3 (large individual). Note complete ridges on scolex and differentiation of testes and vitellaria from each other. E. Stage 4 (small individual). Scolex is well-defined. F. Stage 4 (large individual). There is a male genital pore and postovarian vitellaria are poorly defined. G. Adult stage. Observe the numerous well-defined longitudinal ridges on scolex and welldeveloped postovarian vitellaria. Abbreviations to all figures: ap - apical pouch, ar - apical ring, dv - damaged villi, fp - female pore, fu - furrow, fz - Faserzellen, i - introvert or terminal introvert, 1 - leucocyte infiltration, $1 \mathrm{r}-$ longitudinal ridge, $\mathrm{m}$ - muscle, $\mathrm{mp}$ - male pore, ov - ovary, $\mathrm{p}$ - tissue plug, $\mathrm{pc}$ - primordial cap, pov - postovarian vitellaria, ps - primordial streak, put - primordial uterine tube, $\mathrm{s}$ - dorsoventral slit, $\mathrm{sm}$ - submucosa, $\mathrm{t}-$ testes, $\mathrm{u}$ - uterus, $\mathrm{v}$ - villus, va - vagina, vt - vitellaria, w - worm

vert retracts, a shallow sucker-like structure with a deep slit or fold is formed in a dorsoventral orientation (Fig. 8). Finally, the slit widens to form a deep cavity or apical pouch made by the fully retracted introvert (Figs 6 and 10).

Though the sucker-like structure surrounding the introvert may appear to be acetabular in nature (Fig. 8), mid-sagittal sections of the scolex show that it is not (Fig. 10A, B). No pronounced musculature was found associated with the introvert. However, there appears to be many small, diffuse muscles
(Fig. 10A-C) that, along with similar muscles associated with the ridges, are extensions of the larger bundles of longitudinal muscles at the base of the scolex (Fig. 11A). Within the center of the scolex is a region of lightly stained Faserzellen (Fig. 12).

\section{Attachment and pathology}

Heavily infected fish had darkly stained semi-solid intestinal contents enclosed by a thin mucoid layer separating it from the 

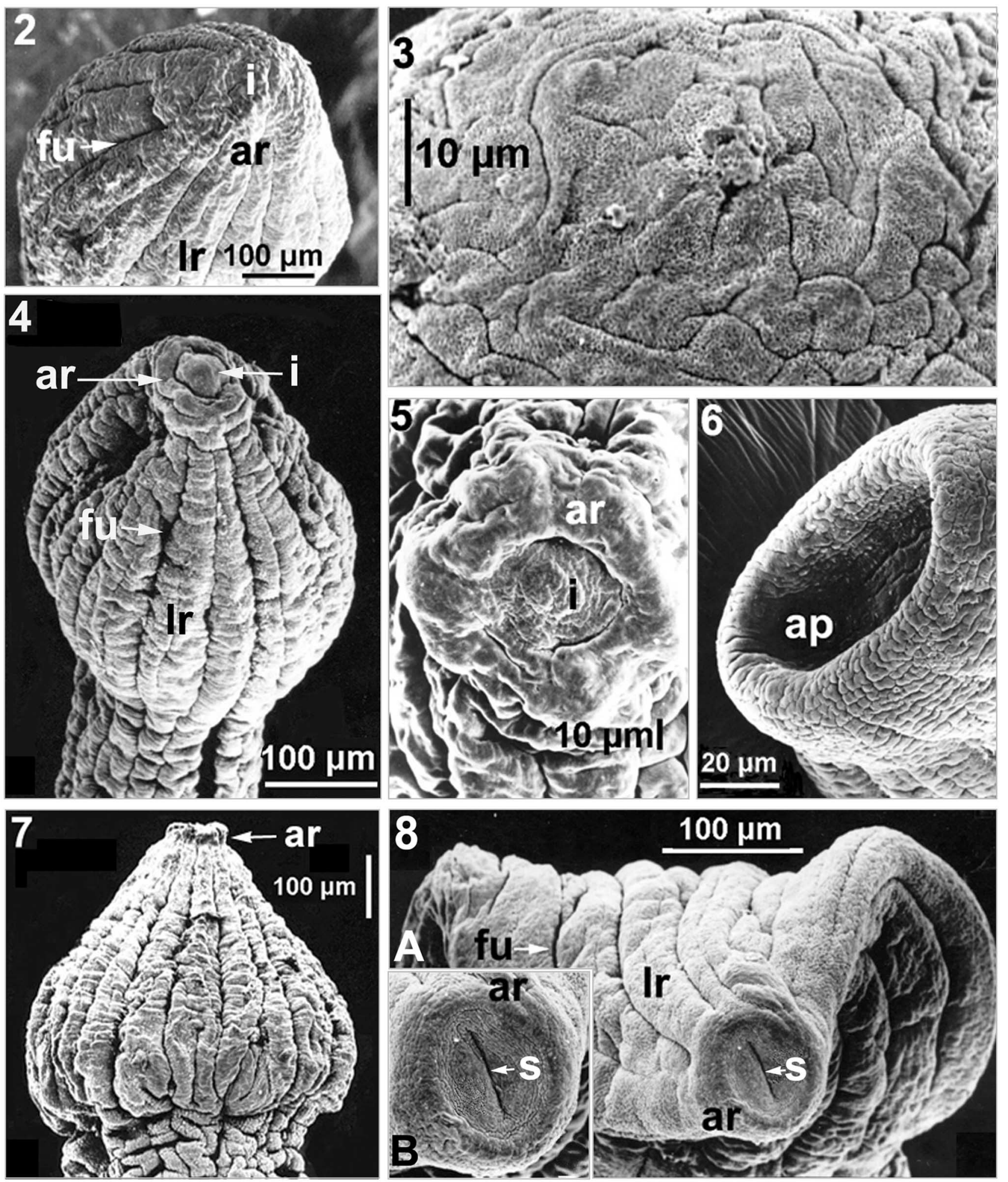

Figs 2-8. SEM of adult Wenyonia virilis. Fig. 2. Scolex with fully extended introvert. Note the faint trace of an apical ring and also the flattened longitudinal ridges separated by shallow furrows. Fig. 3. Surface of the end of an extended introvert showing the corrugated tegument. Fig. 4. Scolex with an introvert partially retracted through the apical ring. Observe the prominent ridges and deep furrows. Fig. 5. Apical view of a partially retracted introvert that is separated from the apical ring by a conspicuous fold. Fig. 6. Scolex apex with a deep, U-shaped apical pouch formed when the introvert is fully retracted. Fig. 7. Scolex showing well-defined longitudinal ridges separated from each other by deep furrows. The apical ring is at the tip of the scolex; the introvert itself is not visible. Fig. 8A. View of a stretching dorsoventrally flattened scolex. Ridges and furrows are especially prominent. Within the shallow sucker-like depression formed by the apical ring and introvert is a dorsoventral slit or fold formed by the retracted introvert. B. Enlarged view of introvert 

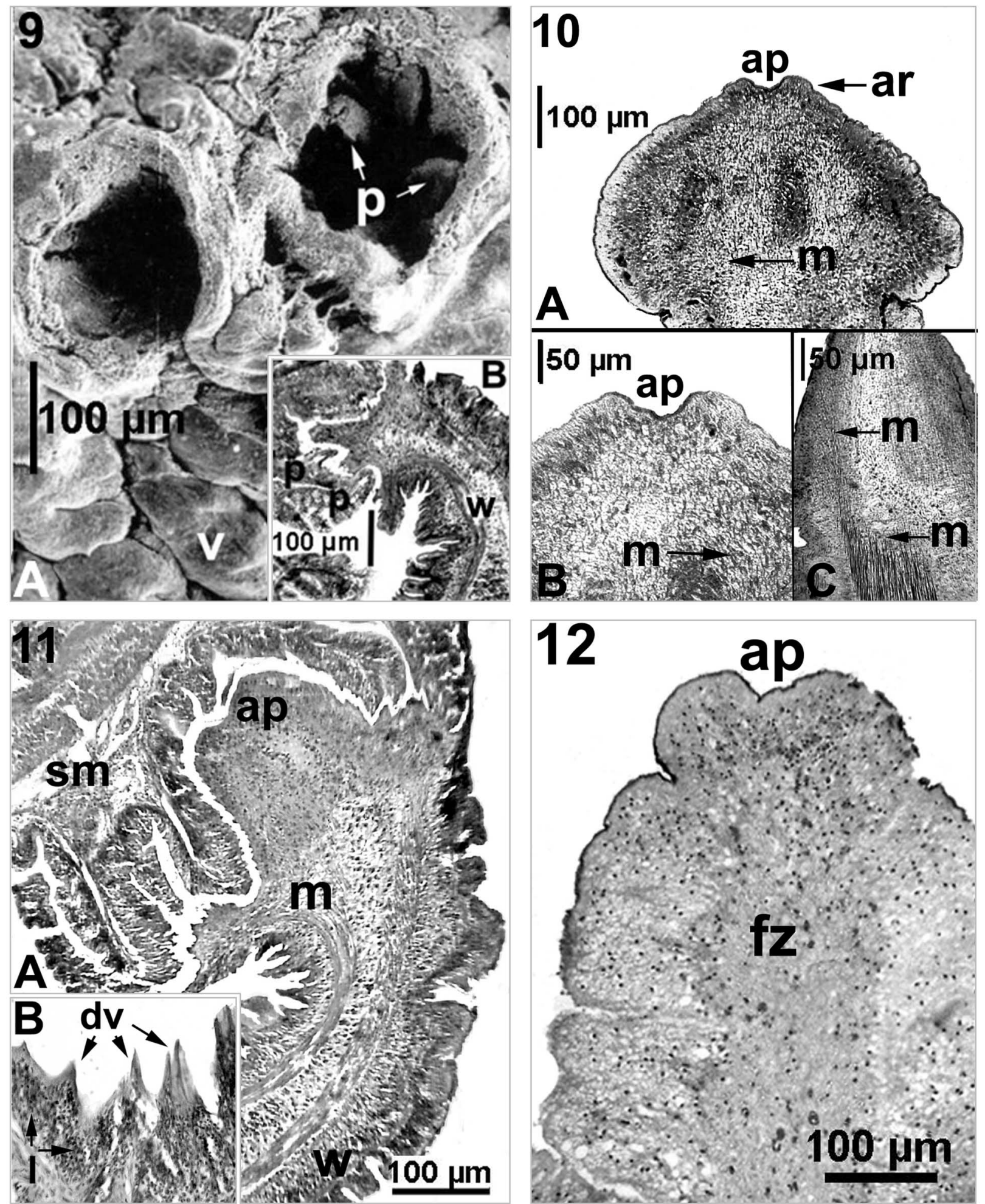

Fig. 9A. SEM of intestinal mucosa of Synodontis schall showing two deep impressions or "footprints" of scolices of detached W. virilis. Within the upper one, there are small protruding portions (tissue plugs) of the mucosa, presumably retracted from the furrows of the scolex. B. Attached scolex with portion of plugs of host tissue in furrows (haematoxylin and eosin stain). Fig. 10A. Sagittal section of W. virilis scolex showing apical pouch. Note the diffuse muscle fibres throughout the scolex. B. Enlargement from Fig. A. Observe the absence of prominent muscles beneath the apical pouch. C. Lower portion of a scolex that shows muscle fibres bending toward tegument (Mallory's triple stain). Fig. 11A. Section of the intestine of $S$. schall showing $W$. virilis superficially attached to intestinal mucosa. Tissue plugs are seen within invaginated parts of scolex. B. Attachment site in $S$. schall with characteristic pointed villi (haematoxylin and eosin stain). Fig. 12. Sagittal section of scolex with lightly stained Faserzellen (toluidine blue stain) 
intestinal mucosa. Juveniles of stages 1 and 2 were free in this layer. All of the remaining stages, including adults, were attached to the intestinal mucosa. Attachment is apparently weak because the great majority of worms readily detached upon fixation. It appears that adult $W$. virilis attach by inserting the scolex into the intervillous spaces and grasping the mucosal tissue using the longitudinal furrows of the scolex (Figs 9 and 11). Scanning electron microscopy of the site of detached adult worms clearly shows the plugs of mucosal tissue that have pulled out of these longitudinal furrows (Fig. 9). It was unclear, however, how the introvert of adult worms functions in attachment.

The pathology resulting from $W$. virilis consists of focal damage, necrosis, degeneration and disruption of the tips of villi, and some vacuolization associated with lymphocytic and leucocytic infiltration into the lamina propria (Fig. 11B). The presence of damaged villi near attached worms indicates that the scolex flares over a wide area (Fig. 11A). Epithelial lining of the intestinal mucosa at the attachment site showed evidence of necrosis and degeneration. Despite the weak attachment, the lamina propria and submucosa in the vicinity of the scolex appeared to have been directly affected by the worm (Fig. 11A). The submucosa showed vacuolization and infiltration with lymphocytes, and polymorphonuclear leucocytes (Fig. 11B).

\section{Discussion}

\section{Development}

Development of the scolex in $W$. virilis is different from that seen in other caryophyllids. Studies on the development of Khawia sinensis Hsü, 1835 by Scholz (1991) and Khawia baltica Szidat, 1942 by Scholz (1993) confirm earlier ones on Archigetes Leuckart, 1878, Biacetabulum Hunter, 1927, Caryophyllaeus Gmelin, 1790, Glaridacris Cooper, 1927, Hunterella Mackiewicz et McCrae, 1962 and Monobothrium Diesing, 1863 (see review by Mackiewicz 1972: figs 85-98) in that the adult scolex morphology of these caryophyllideans is established in the infective, procercoid stage within the oligochaete intermediate host. In these cases, the presence of scolex specializations such as acetabula, loculi, fimbrii, bothria or introvert, are readily apparent at the time genital primordia appear and the larva has a cercomer. In W. virilis, on the other hand, the earliest stages recovered from fish (stages 1 and 2) were seen to exhibit a large scolex, with a terminal introvert (Fig. 1A, B), that lacked the longitudinal ridges so characteristic of the adult scolex. In his figures of immature worms of W. virilis, Woodland (1923, pl. 24, figs 14 and 15) did not show any ridges or a terminal introvert. It is not until the larva is over $5 \mathrm{~mm}$ long (Fig. 1C) that the scolex ridges begin to appear, increasing in size and number as the worm matures (Fig. 1D-G). These data indicate that development of the basic form of the adult scolex in $W$. virilis is delayed until the worm is in the vertebrate host. This is in stark contrast to the advanced development of the scolex in progenetic Archigetes (see Poddubnaya et al. 2003) and other genera as noted above. Despite the lack of information on development of Wenyonia within the intermediate host, our data indicate that this species exhibits less of a tendency toward progenesis than of any other known caryophyllid.

\section{Morphology}

Morphology of the scolex of $W$. virilis is variable (Woodland 1923) because the scolex is highly mobile and the terminal introvert is capable of protrusion and retraction. In his generic diagnosis for Wenyonia, Ukoli (1972: p. 60) wrote, "Scolex undifferentiated, with longitudinal grooves, or with pointed anterior projection which when retracted forms a cavity which acts as a sucker". Unfortunately, both Woodland and Ukoli worked with flattened specimens, a condition that accentuates the grooves or creases and flattens the ridges. Our unflattened material (Figs 2, 4, 7 and 8) clearly show the ridges or rugae that characterize this scolex. The number of ridges is variable with a range of 13-14 for small adults (14.5-16 mm) to 16-19 for larger adults (17-20 mm). Both Woodland (1923) and Garo et al. (2000) reported 13-26 creases or grooves, a range that translates to 12-25 ridges. We have used the scolex terminology of Hamada and El-Naggar (2003), rather than that of Woodland (1923) and Ukoli (1972) and thus "furrows" is used instead of "grooves" and "creases".

At the most anterior end of the scolex of $W$. virilis is the terminal introvert. It is a mobile, protrusible structure that lies within an apical ring formed at the confluence of the ridges at the scolex apex (Figs 4, 6 and 8). Kulmatycki (1924) considered that the anterior part of the scolex functions as a kind of primitive suctorial disc. This disc or sucker-like structure of $W$. virilis, formed by the apical ring, may appear to be acetabular in nature, however, mid-sagittal sections show that it lacks any distinct musculature of its own (Fig. 10). Traces of the apical ring remain, however, when the introvert is fully extended (Fig. 2). Khalil (1995) observed the same structure associated with the fully extended introvert of Monobothrioides woodlandi Mackiewicz et Beverley-Burton, 1967. As recognized by Woodland (1924) and elaborated by Hamada and El-Naggar (2003), the terminal introvert of W. virilis is basically similar to that of Monobothrioides chalmersus, though smaller and less well-developed. It is quite different, however, from the apical structure of Djombangia, described by Bovien (1926: p. 161) as a "...distinctly marked circular sucker ..." with a "...specially developed musculature". Fuhrmann (1931), on the other hand, regarded this terminal structure as glandular, rather than acetabular in nature. The introvert on the truncated scolex of Monobothrium spp. lacks an apical ring (Mackiewicz 1963) and, in the case of some worms (e.g. M. ulmeri), may occupy the entire anterior end of the truncated scolex (Calentine and Mackiewicz 1966), or in other cases, may exhibit a pair of accessory shallow loculi or bothria on the scolex (Mackiewicz 1994). The terminal funnel of the choanocampanulate scolex of Caryoaustralus is small 
and lacks any trace of an apical ring (Mackiewicz and Blair 1980).

In light of the present study, in which a distinct terminal introvert is described, it is necessary to change the previous designation of "rugomontanate" for the scolex of Wenyonia (Mackiewicz 1994) to "rugomonobothriate", the term used to describe the scolex of Monobothrioides.

\section{Mode of attachment}

The exact mode of attachment of $W$. virilis is unclear but appears to involve the terminal introvert, and to a greater extent, the longitudinal ridges and furrows. In W. longicauda, the scolex holds the mucosa by retracting the protrusible tip to form a rim and cavity that acts as a large, though feeble sucker (Woodland 1937). The primary means of attachment of adult worms of $W$. virilis appears different from that described in M. chalmersius by Hamada and El-Naggar (2003). Unlike $M$. chalmersius, that is firmly attached by mucosa drawn into the longitudinal furrows as well as the apical and lateral pouches formed by the introvert (Hamada and El-Naggar 2003), attachment in $W$. virilis is primarily by the furrows. We did not find pouches associated with the introvert in W. virilis (Fig. 11). Since the introvert of $W$. virilis is less well-developed than that of Monobothrioides, it does not assume a major attachment function in the adult cestode. It may, however, play a greater role in juvenile worms that may attach by the introvert in the absence of furrows on the scolex.

As Woodland (1923) observed and we confirm, there are numerous transverse and longitudinal muscle fibres scattered throughout the scolex of W. virilis (Figs 10A-C and 11). These fibres, therefore, are not arranged into discreet bundles since they appear to attach along the length of each ridge and furrow. Ridge flexibility and action may be promoted by the longitudinal fibres that are an extension of the annular inner longitudinal muscle bundles that flare out into the scolex and connect to the inside of the ridges and introvert (Figs 10C and 11A). In M. chalmersius, there are said to be two bundles of inner longitudinal muscles in the scolex that branch to the introvert and surrounding tegument (Hamada and El-Naggar 2003). Furthermore, these two bundles are also said to extend to the posterior region of the body, a fact not supported by the annular arrangement of the numerous inner and outer longitudinal muscle bundles clearly evident in cross-sections through the testicular field (Woodland 1924: fig. 4).

Whether attachment may be influenced by the Faserzellen that appear as a column of cells that extend from the central part of the scolex posteriorly to the testes and vitellaria (Fig. 12 ) is something yet to be determined. Concentrations of these neck cells or Faserzellen were not observed in W. virilis by Woodland (1923). Faserzellen are well-known in caryophyllideans, however, having been described in a diversity of other caryophyllids (Hayunga 1979, Hayunga and Mackiewicz 1988). Ultrastructural studies have shown Faserzellen to be glandular with ducts to the neck and scolex tegument (Richards and Arme 1981, Kuperman and Davydov 1982, Pod- dubnaya et al. 2003). Such cells were not observed by Hamada and El-Naggar (2003) in the neck of M. chalmersius, however, they did report gland cells just beneath the tegument as well as small openings on the apical region of the introvert. Small openings in the pit of the holdfast of $W$. virilis were also reported by Garo et al. (2000). We were unable to positively identify openings in the surface of the introvert tip using SEM (Fig. 3). Indeed, detailed study of $W$. virilis at the ultrastructural level is needed to establish the extent to which the glandular elements of the introvert and other parts of the scolex may be involved in attachment.

The pathology caused by $W$. virilis is similar to that described by Banhawy et al. (1975), however, it differs significantly from that of other caryophyllideans with an introvert or other apical structure on the scolex. Since it is not firmly attached, $W$. virilis may be capable of changing attachment sites. This is clearly not the case with Monobothrium, however. Both $M$. ingens and M. ulmeri, for example, may be embedded in large, conspicuous nodules with active, chronic inflammatory tissue (Mackiewicz et al. 1972). Even in heavy infections of W. virilis, no nodules were formed (Banhawy et al. 1975). The conspicuous serosal capsule formed by each scolex of Djombangia is well documented (Bovien 1926, Satpute and Agarwal 1974) and supports a glandular (i.e. secretive) rather than sucker (i.e. mechanical) function for the terminal structure. Though $M$. hunteri does not form nodules, it is firmly anchored to the submucosa (Mackiewicz 1963). In the case of $M$. chalmersius, that has furrows on the scolex like that of $W$. virilis, the attachment is firm with disruption, and sometimes vacuolation of the lamina propria as well as necrosis and degeneration of the columnar epithelium (Hamada and ElNaggar 2003). Much of the pathology caused by W. virilis appears to be from physical contact. We found no evidence of the production of adhesive substances.

The unique mode of attachment described here for $W$. virilis and for M. chalmersius by Hamada and El-Naggar (2003) is not found in any other caryophyllidean genus. Furthermore, both species conform to the inverse relationship between scolex specialization and host pathology as shown by the study of attachment of 15 other caryophyllean species (Mackiewicz et al. 1972). The list of structures observed in caryophyllid species for attachment to the host mucosa, which currently consists of bothria, acetabula, fimbrii, loculi and terminal introvert should now be expanded to include the combination of longitudinal ridges and furrows.

Acknowledgements. The assistance of members of the Electron Microscope Unit, Central Laboratory of Assiut University, in viewing the specimens on the stereoscan is gratefully acknowledged.

\section{References}

Banhawy M.A., Anwar I.M., Naffar M.K. 1979. Histochemical studies on the ileum and liver of the silurid fish, Synodontis schall infected with the tapeworm, Wenyonia virilis. Proceedings of the Egyptian Academy of Sciences, 29, 59-66. 
Banhawy M.A., Saoud M.F., Anwar I.M., Naffar M.K. 1975. The histopathological effects of the parasitic tapeworm Wenyonia virilis on the ileum and liver of the silurid fish Synodontis schall. Annals of Zoology, 11, 83-101.

Bovien P. 1926. Caryophyllaeidae from Java. Videnskabelige Meddelelser fra Dansk Naturhistorisk Forening i København, 82, 157-181.

Calentine R.L., Mackiewicz J.S. 1966. Monobothrium ulmeri n. sp. (Cestoda: Caryophyllaeidae) from North American Catostomidae. Transactions of the American Microscopical Society, 85, 516-520.

Chervy L. 2002. The terminology of larval cestodes or metacestodes. Systematic Parasitology, 52, 1-33.

El-Naffar M.K., Saoud M.F., Hassan I.M. 1983. A general survey of the helminth parasites of some fishes from Lake Nasser at Asswan, A.R. Egypt. Assiut Veterinary Medical Journal, 11, 139-148.

Fahmy M.A.M., Mandour A.M., El-Naffar M.K. 1976. On some cestodes of the fresh water fishes in Assiut province, Egypt. Veterinary Medical Journal, 24, 253-262.

Fuhrmann O. 1931. Dritte Klasse des Cladus Plathelminthes: Cestoidea. In: Handbuch der Zoologie (Eds. W. Kükenthal and T. Krumbach). W. de Gruyter and Co., Berlin, 2(1933), 141256.

Garo K.V., Bashtar A.R., Sameh I. 2000. Scanning electron microscopical study on some parasitic helminthes from freshwater fishes in Helwan, Southern Cairo. Journal of the Egyptian German Society of Zoology, 33 (D), 117-131.

Hamada S.F., El-Naggar M.M. 2003. Surface topography, mode of attachment and histopathology of Monobothrioides chalmersius (Cestoidea: Caryophyllidea) from Clarias gariepinus in Egypt. Egyptian Journal of Zoology, 40, 185-201.

Hayunga E.G. 1979. The structure and function of the scolex glands of three caryophyllid tapeworms. Proceedings of the Helminthological Society of Washington, 46, 171-179.

Hayunga E.G., Mackiewicz J.S. 1988. Comparative histology of the scolex and neck of Glaridacris laruei (Lamont, 1921) Hunter, 1927 and Glaridacris catostomi Cooper, 1920 (Cestoidea: Caryophyllidea). Canadian Journal of Zoology, 66, 790-803.

Imam E.A.E., El-Askalany M.A., Rashad S.M. 1991. Studies on helminth parasites of Synodontis schall and Bagrus bayad from Beni-Suef water resources. Assiut Veterinary Medical Journal, 24, 137-152.

Khalil A.I. 1995. Ultrastructural comparison of the tegument of Monobothrioides woodlandi Mackiewicz and Beverley Burton, 1967 (Caryophyllidea) and pseudophyllid plerocercoid. Proceedings of the Zoological Society A.R. Egypt, 26, 66-81.

Khalil L.F., Polling L. 1997. Check list of the helminth parasites of African freshwater fishes. Department of Zoology/Biology, University of the North, Pietersburg, Republic of South Africa.

Kulmatycki W.J. 1924. Caryophyllaeus niloticus nov. sp. Results of the Swedish Zoological Expedition to Egypt and the White Nile 1901, Nr 27A, 1-19.
Kuperman B.I., Davydov V.G. 1982. The fine structure of frontal glands in adult cestodes. International Journal for Parasitology, 12, 285-293.

Mackiewicz J.S. 1963. Monobothrium hunteri sp. n. (Cestoidea: Caryophyllaeidae) from Catostomus commersoni (Lacépède) (Pisces: Catostomidae) in North America. Journal of Parasitology, 49, 723-730.

Mackiewicz J.S. 1972. Caryophyllidea (Cestoidea): A review. Experimental Parasitology, 31, 417-512.

Mackiewicz J.S. 1994. Order Caryophyllidea van Beneden in Carus, 1863. In: Keys to the cestode parasites of vertebrates (Eds. L.F. Khalil, A. Jones and R.A. Bray). CAB International, Wallingford, U.K., 21-43.

Mackiewicz J.S., Blair D. 1980. Caryoaustralus gen. n. and Tholophyllaeus gen. n. (Lytocestidae) and other caryophyllid cestodes from Tandanus spp. (Siluriformes) in Australia. Proceedings of the Helminthological Society of Washington, 47, $168-178$.

Mackiewicz J.S., Cosgrove G.E., Guide W.D. 1972. Relationship of pathology to scolex morphology among caryophyllid cestodes. Zeitschrift fürParasitenkunde, 39, 233-246.

Poddubnaya L.G., Mackiewicz J.S., Kuperman B.I. 2003. Ultrastructure of Archigetes sieboldi (Cestoda: Caryophyllidea): relationship between progenesis, development and evolution. Folia Parasitologica, 50, 275-292.

Richards K.S., Arme C. 1981. The ultrastructure of the scolex-neck syncytium, neck cells and frontal gland cells of Caryophyllaeus laticeps (Caryophyllidea: Cestoda). Parasitology, 83, 477-487.

Satpute L.R., Agarwal S.M. 1974. 'Diverticulosis' of the fish duodenum infested with cestodes. Indian Journal of Experimental Biology, 12, 373-375.

Scholz T. 1991. Early development of Khawia sinensis Hsü, 1935 (Cestoda: Caryophyllidea). Folia Parasitologica, 38, 133142.

Scholz T. 1993. On the development of Khawia baltica Szidat, 1942 (Cestoda: Lytocestidae), a parasite of tench, Tinca tinca (L.). Folia Parasitologica, 40, 99-103.

Ukoli F.M.A. 1972. Occurrence, morphology and systematics of caryophyllaeid cestodes of the genus Wenyonia Woodland, 1923 from fishes in River Niger, Nigeria. Journal of the West African Science Association, 17, 49-67.

Woodland W.N.F. 1923. On some remarkable new forms of Caryophyllaeidae from the Anglo-Egyptian Sudan, and a revision of the families of the Cestodaria. Quarterly Journal of the Microscopical Science (New Series), 67, 435-472.

Woodland W.N.F. 1924. On a new species of the cestodarian genus Caryophyllaeus from an Egyptian siluroid. Proceedings of the Zoological Society of London, (1924), 529-532.

Woodland W.N.F. 1937. Some cestodes from Sierra Leone. I. On Wenyonia longicauda sp. n., and Proteocephalus bivitellatus sp. n. Proceedings of the Zoological Society of London, (1936), 931-937. 